\title{
Nutritional Evaluation of Indigenous Plants and Quantification of Total Saponins in Plant Extracts
}

\author{
Anamika $^{1}$, K.K. Singhal ${ }^{1}$, A.K. Singh ${ }^{1}$ and Shilpi Kerketta ${ }^{2 *}$ \\ ${ }^{1}$ Animal Nutrition Division, ICAR- National Dairy Research Institute, \\ Karnal- 132001, Haryana, India \\ ${ }^{2}$ Livestock Production Management, ICAR-National Dairy Research Institute, \\ Karnal-132001, Haryana, India \\ *Corresponding author
}

\begin{tabular}{|c|c|}
\hline \multicolumn{2}{|r|}{ A B S T R A C T } \\
\hline & \multirow{6}{*}{$\begin{array}{l}\text { Present study was conducted for nutritional evaluation of indigenous plants like Reetha } \\
\text { (Sapindus mukoressi), Shikakai (Acacia concinna), Mahua cake (Madhuca indica), Albizia } \\
\text { leaves (Albizia lebbeck) and Yucca (Yucca schidigera) leaves, stem and roots and } \\
\text { quantification of total saponins in plant extracts. Ground samples were analyzed for } \\
\text { proximate principles, viz., dry matter (DM), organic matter (OM), crude protein (CP), } \\
\text { ether extract (EE) and total ash (TA). Among all extracts the organic matter content in } \\
\text { Yucca roots (98.42\%) was highest whereas in Albizia leaves it was lowest }(88.14 \%) \text {. The } \\
\text { CP content of Albizia leaves was higher (19.15\%) followed by Mahua cake }(16.96 \%) \text { than } \\
\text { those of other plant materials. But, EE content of Mahua cake (6.93\%) was higher than in } \\
\text { Albizia leaves ( } 3.98 \%) \text {. Total saponins content of Reetha, Shikakai, Mahua cake and } \\
\text { Albizia leaves were found to be } 8.74,11.79,7.34 \text { and } 3.75 \% \text {, respectively. Total saponins } \\
\text { content in various parts of Yucca plant i.e. leaves, root and stem was found to be } 3.74,4.02 \\
\text { and } 2.80 \% \text {, respectively. Nitrogen content (mg/ml) in plant extract of Reetha, Shikakai, } \\
\text { Mahua cake, Albizia leaves and Yucca root was found to be } 2.59 \text {, } 1.96,0.98,1.33 \text { and } \\
1.68 \text {, respectively. Thus it can be concluded that these indigenous plants extracts rich in } \\
\text { saponins and can be employed to modify rumen microbial fermentation. }\end{array}$} \\
\hline & \\
\hline & \\
\hline Ar & \\
\hline & \\
\hline & \\
\hline
\end{tabular}

\section{Introduction}

Manipulation of rumen microbial ecosystem for enhancing the digestibility of fibrous feeds and nitrogen utilization and reducing methane emission in ruminants to improve their performance are some of the most important goals for animal nutritionists; as sizeable losses take place during the digestion of dietary carbohydrates and proteins. Natural antimicrobials such as plant extracts are generally considered as safe for human consumption (FDA, 2004) and these can be employed to modify rumen microbial fermentation. The extracts of leaves, fruits or roots of various plants are traditionally used as medicine and food-preservation in India since ages and these have been recognized as having antimicrobial and anti-methanogenic properties (Davidson and Naidu, 2000; Alexander, 2005; Malik, 2007) due to the presence of plant secondary metabolites such as saponins, terpenoids, phenylpropanoids, tannins etc. Many researchers have 
demonstrated the potential of plant extracts in modification of rumen microbial fermentation but concluded that the doses used may have not been adequate (Cardozo et al., 2004; Busquet et al., 2005). The tropical plants containing saponins have been found to inhibit ruminal protozoa, increase duodenal protein flow, reduce methane and ammonia production (Kamra et al., 2000; Sliwinski et al., 2002; Lila et al., 2003; Malik, 2007, Patra and Saxena, 2009b) thereby increasing productivity of the ruminants. However, effectiveness of plants or plant extracts having high content of saponins depends upon the source, type and quantity of secondary metabolites present in it.

Hence, it becomes important to explore the potential of various plant extracts for their antiprotozoal and antimethanogenic properties by estimating total saponins present in them. Information about the nutritional composition of various indigenous plants which are in abundance in India is scanty, and knowledge regarding the level of saponins present in them is also inadequate. Therefore, the present study was undertaken to explore the nutrient contents of different indigenous plant materials which are rich in saponins and furthermore, to determine the amount of total saponins present in them.

\section{Materials and Methods}

\section{Collection of the plant or herbal materials}

Samples of the Reetha and Shikakai pods were purchased from the local market and their pulp was separated from the seed(s) and dried in a hot air oven. Mahua cake was purchased from an authentic supplier of nonconventional oil-cakes. Leaves of Albizia were collected from a tree and dried first under sunlight and then in oven. Whole Yucca plant, including its roots, was collected from the nursery of National Dairy Research
Institute, Karnal and its different fractions i.e. leaves, stem and roots were separated and each fraction was thereafter dried in the oven.

\section{Preparation of the plant materials}

The samples of plant materials used in the study were ground $(1 \mathrm{~mm})$ using a Willey Mill. Ground samples were analyzed for proximate principles, viz., dry matter (DM), organic matter (OM), crude protein (CP), ether extract (EE) and total ash (TA) as per standard procedures of Association of Official Analytical Chemists (AOAC,1995). All the samples were also analyzed for the cell-wall components as per Van Soest et al., (1985).

\section{Preparation of plant extract}

Plant extract of different samples were prepared and analyzed for the total saponins content as per the method given by Dr. S. B. Mahato, Institute of Chemical Biology, Kolkata.

Finely ground sample $(50 \mathrm{gm})$ was taken into a $1000 \mathrm{ml}$ flask and $500 \mathrm{ml}$ of $50 \%$ methanol was added. The flask was kept on a magnetic stirrer for 6-7 hours, followed by centrifuging the contents at $3000 \mathrm{~g}$ for $10 \mathrm{~min}$. at $4^{\circ} \mathrm{C}$ and supernatant was collected. Extraction process was repeated with the same solvent by constant stirring with a magnetic stirrer. After centrifugation, both the supernatants were combined. Methanol was evaporated from the solution under in vacuo condition using a rota-evaporator. Aqueous phase was centrifuged again at $3000 \mathrm{~g}$ for $10 \mathrm{~min}$. at $4^{\circ} \mathrm{C}$ to remove the water insoluble materials. Aqueous phase was transferred in to a separating funnel and extracted with equal volume of chloroform (3 times) for the removal of pigments. Finally concentrated saponins in the aqueous solution $(10 \mathrm{ml})$ were extracted with equal volume of n-butanol (2 times). The solvent, n-butanol was evaporated 
under in vacuo condition with a temperature not higher than $45^{\circ} \mathrm{C}$. Dissolved the dried saponins in 5-10 $\mathrm{ml}$ of distilled water and transferred the solution into a separate preweighed container. The fractions were freeze dried and percent recovery (yield) of crude saponins extract was calculated.

\section{Estimation of total saponins}

For estimation of total saponins content in different plant materials, method recommended by Hiai et al., (1976) was followed.

\section{Reagents}

Vanillin reagent $(8 \%, \mathrm{w} / \mathrm{v})$ : Vanillin $(800 \mathrm{mg})$ was dissolved in $10 \mathrm{ml}$ of $99.0 \%$ ethanol (analytical grade)

$72 \%$ (v/v) sulphuric acid: $72 \mathrm{ml}$ of sulphuric acid (analytical grade, 95\%, w/w) was added to $28 \mathrm{ml}$ of distilled water

\section{Standard saponins solution}

$50 \mathrm{mg}$ Quillaja saponins (Sigma-Aldrich) was dissolved in $80 \mathrm{ml}$ of methanol and $20 \mathrm{ml}$ water was added to it. The final concentration of saponins in the solution was $0.5 \mathrm{mg} / \mathrm{ml}$ of $80 \%$ methanol. Pipetting was done immediately.

\section{Preparation of standard curve}

Saponin quantity varied in the range of $0-125$ $\mu \mathrm{g}$ dissolved in $0.25 \mu \mathrm{l}$ of $80 \%$ methanol were taken in different test tubes to which $0.5 \mathrm{ml}$ of vanillin reagent was added. Tubes were placed in ice-cold water bath and $2.5 \mathrm{ml}$ of sulphuric acid was added slowly on the inner side of the wall. After mixing the content in each tube, these were left as such for $3 \mathrm{~min}$. Warmed the tubes to $60^{\circ} \mathrm{C}$ for 10 min using a water bath and then cooled them in ice-cold water bath. Absorbance was measured at 544 nm using spectrophotometer (Varian, model Cary 1) against the reagent blank and prepared the standards curve.

\section{Determination of samples}

Dissolved known amount of extracted saponins residues in $80 \%$ methanol. From this, an aliquot of $0.25 \mu 1$ was taken from each sample and determination was carried out as for the standard saponins.

\section{Results and Discussion}

\section{Chemical composition of plant materials}

The proximate compositions and cell wall fractions of different plant materials (on \% DM basis) used during in vitro study have been presented in table 1 .

The organic matter content in Yucca roots (98.42\%) was highest whereas in Albizia leaves it was lowest $(88.14 \%)$. The organic matter content in all other plant materials such as Reetha powder $(96.06 \%)$, Shikakai powder $(95.62 \%)$ and Mahua cake $(94.42 \%)$ was almost similar (Figs. 1-6). The CP content of Reetha, Shikakai, Mahua cake, Albizia leaves and Yucca roots was 3.13, 5.28, 16.96, 19.15 and 4.20 per cent, respectively, which showed that the Mahua cake and Albizia leaves were having higher $\mathrm{CP}$ content than those of other plant materials. Reetha was having lowest $\mathrm{CP}$ content. Similarly, EE content of Mahua cake $(6.93 \%)$ was higher than in Albizia leaves (3.98\%). Other plant materials under investigation were containing negligible EE content. Similar CP and EE content in Mahua cake was reported by Chahil et al., (1987). Total carbohydrate content of the plant materials under study followed the reverse trend of their EE content. The NDF content in these plant materials varied in a narrow range except that of Albizia leaves, which was 
having highest NDF content (41.44\%), which may be attributed to the maturity stage of the leaves as these were collected during the month of January and the new leaves appeared in the month of March. Though the Reetha powder, Shikakai powder and Yucca roots were having high carbohydrates content, but their NDF content was fairly low, which showed that these plant materials were rich in soluble carbohydrates. Hemi-cellulose content in Shikakai was lowest $(3.42 \%)$, while it was highest in Albizia leaves (11.83\%). Babayemi et al., (2004) reported that OM, CP, NDF and $\mathrm{EE}$ in Albizia leaves ranged between 94.6 97.0\%, 24.8- 38.2 \%, 22.1- $46.9 \%$ and 2.0$17.0 \%$, respectively, and the present values were well in the given range.

\section{Yield of plant extracts}

Yield of plant extracts from various plant materials (\% DM basis) is depicted on table 2 .
Yield of plant extracts after freeze-drying for Reetha, Shikakai, Mahua cake, Albizia leaves and Yucca leaves, root and stem was found to be $16.05,16.04,11.37,8.18,8.77,6.28$ and 10.09 per cent, respectively(on \% DM basis). Alexander (2005) reported that the plant extract yield (\% DM) of 25 medicinal plants on extraction with aqueous, $50 \%$ aqueous methanol and $50 \%$ aqueous acetone varied between plants and also between different solvents. Highest yield was observed for aqueous acetone extract of $E$. officinalis fruit $(54.10 \%)$ while it was lowest in B. aristata root aqueous extract $(2.72 \%)$.

\section{Total saponins content of plant materials}

Total saponins content of Reetha, Shikakai, Mahua cake, Albizia leaves and different fractions of Yucca plant such as leaves, stem and roots on \% DM basis have been presented in table 3 .

Table.1 Chemical composition of plant materials (\% DM basis)

\begin{tabular}{|l|c|c|c|c|c|}
\hline Attributes & $\begin{array}{c}\text { Reetha } \\
(\mathbf{R})\end{array}$ & $\begin{array}{c}\text { Shikakai } \\
(\mathbf{S})\end{array}$ & $\begin{array}{c}\text { Mahua } \\
\text { cake (M) }\end{array}$ & $\begin{array}{c}\text { Albizia } \\
\text { leaves (A) }\end{array}$ & $\begin{array}{c}\text { Yucca root } \\
(\mathbf{Y})\end{array}$ \\
\hline OM & 96.06 & 95.62 & 94.42 & 88.14 & 98.42 \\
\hline CP & 3.13 & 5.28 & 16.96 & 19.14 & 4.20 \\
\hline EE & 0.97 & 0.56 & 6.93 & 3.98 & 0.82 \\
\hline TCHO & 91.96 & 90.34 & 70.53 & 65.02 & 93.40 \\
\hline TA & 3.94 & 4.38 & 5.58 & 11.86 & 1.58 \\
\hline NDF & 16.84 & 17.08 & 21.49 & 41.44 & 23.34 \\
\hline ADF & 9.41 & 13.66 & 12.95 & 29.61 & 18.63 \\
\hline Hemicellulose & 7.43 & 3.42 & 8.54 & 11.83 & 4.71 \\
\hline
\end{tabular}

Table.2 Yield of plant extracts from various plant materials (\% DM basis)

\begin{tabular}{|l|l|l|c|}
\hline Name & Scientific name & Plant part & Yield (\% DM basis) \\
\hline Reetha & Sapindus mukoressi & Pulp & 16.055 \\
\hline Shikakai & Acacia concinna & Pulp & 16.04 \\
\hline Mahua cake & Madhuca indica & Cake & 11.37 \\
\hline Siris & Albizia lebbek & Leaves & 8.18 \\
\hline Yucca & Yucca schidigera & Leaves & 8.77 \\
\hline Yucca & Yucca schidigera & Root & 6.28 \\
\hline Yucca & Yucca schidigera & Stem & 10.09 \\
\hline
\end{tabular}


Table.3 Total Saponins content in plant extracts of different plant materials

\begin{tabular}{|l|c|c|}
\hline Name & Total saponins (\%DM Basis) & N content $(\mathbf{m g} / \mathbf{m l})$ \\
\hline Reetha $(\mathrm{R})$ & 8.74 & 1.59 \\
\hline Shikakai $(\mathrm{S})$ & 11.79 & 1.96 \\
\hline Mahua cake $(\mathrm{M})$ & 7.34 & 0.98 \\
\hline Albizia Leaves $(\mathrm{A})$ & 3.75 & 1.33 \\
\hline Yucca leaves & 3.74 & - \\
\hline Yucca root $(\mathrm{Y})$ & 4.02 & 1.68 \\
\hline Yucca stem & 2.80 & - \\
\hline
\end{tabular}

Table.4 Volume of plant extracts $(\mu 1)$ used to achieve different levels of saponins in substrate

\begin{tabular}{|l|c|c|}
\hline Plant extract & $2 \%$ level & $4 \%$ level \\
\hline Reetha (R) & 230 & 460 \\
\hline Shikakai (S) & 170 & 340 \\
\hline Mahua cake (M) & 270 & 540 \\
\hline Albizia leaves (A) & 530 & 1060 \\
\hline Yucca root (Y) & 500 & 1000 \\
\hline
\end{tabular}

Fig.1 Mahua (Madhuca indica) cake

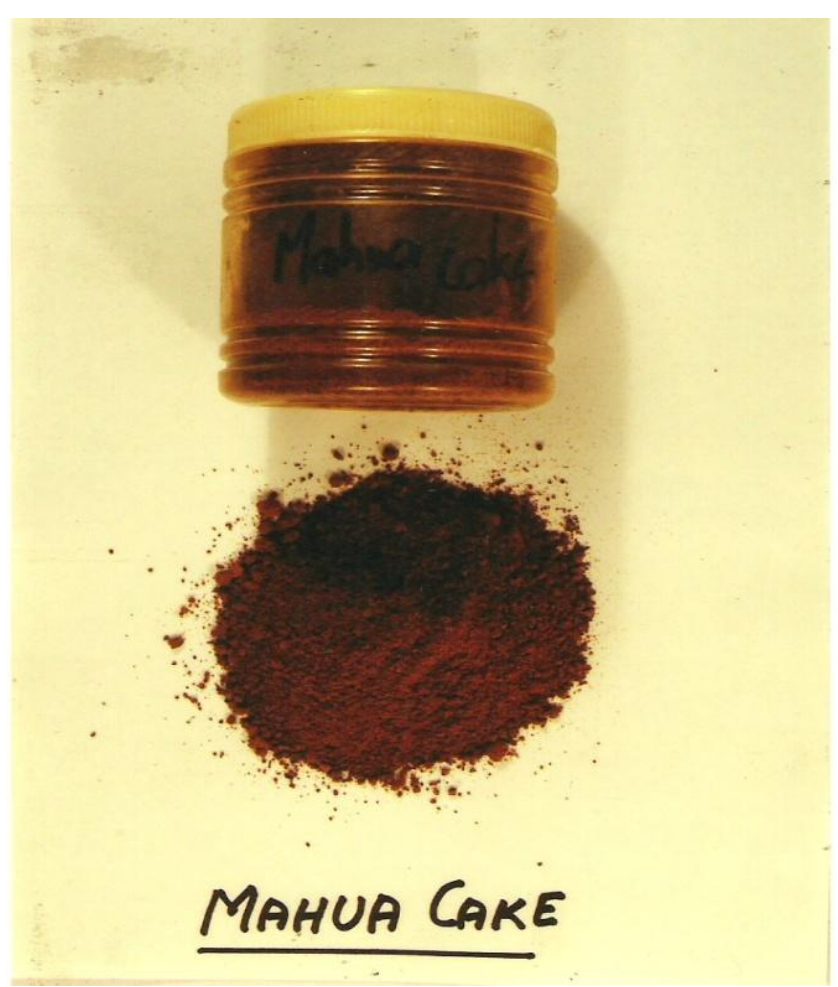


Fig.2 Shikakai (Acacia concinna) pulp and pods

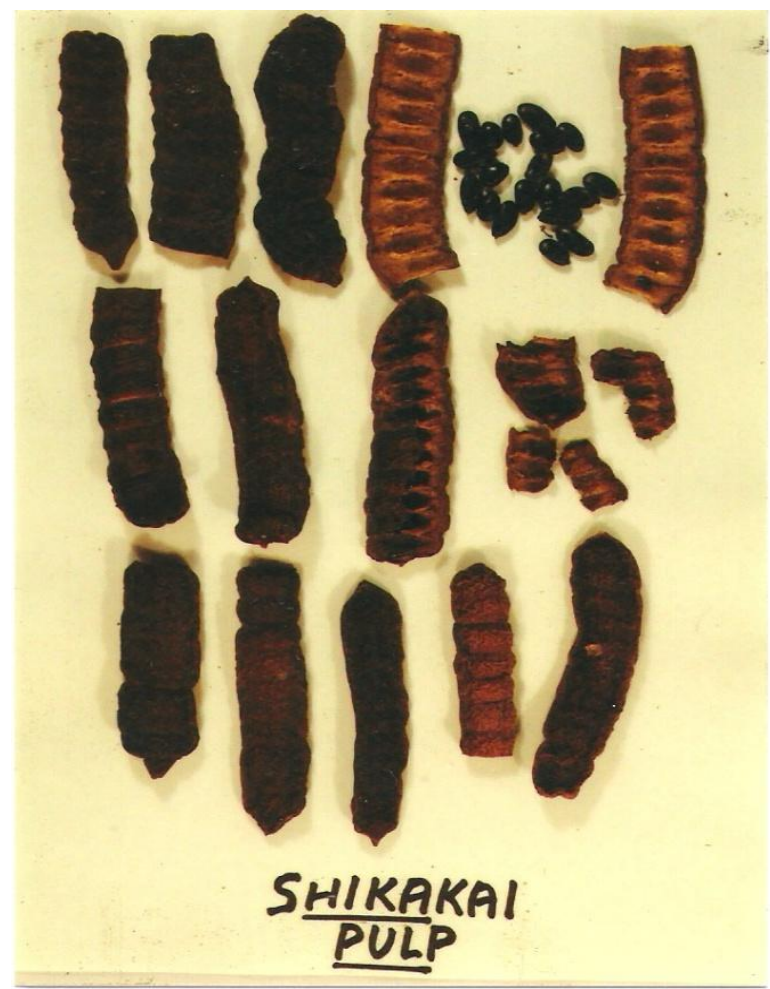

Fig.3 Reetha (Sapindus mukoressi) pulp and pods

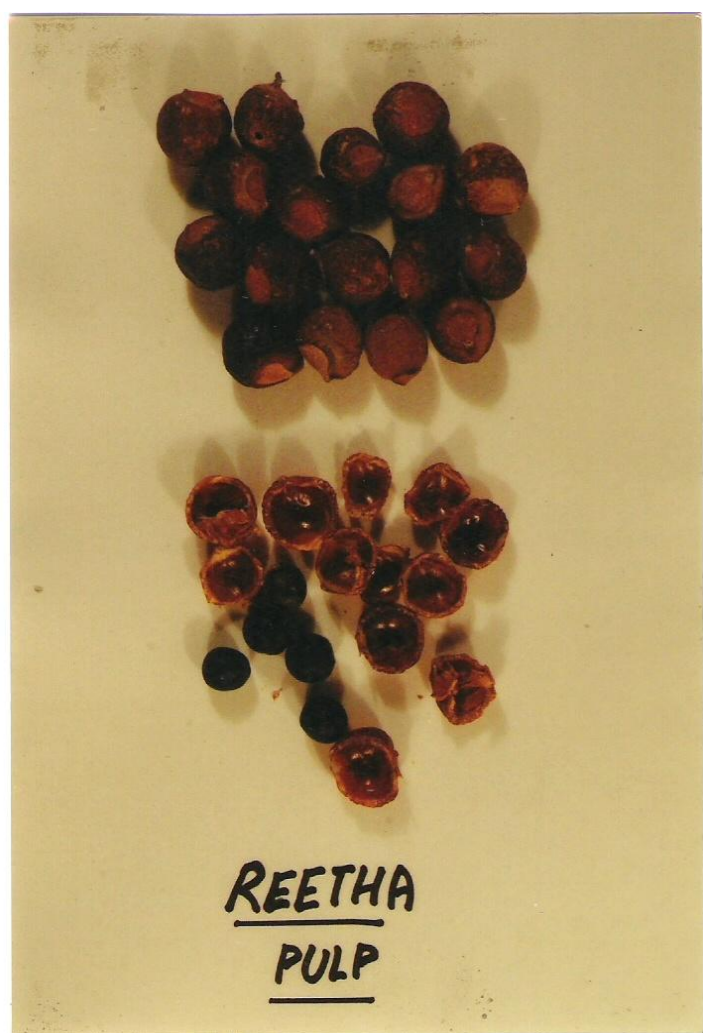


Fig.4 Yucca (Yucca schidigera) whole plant

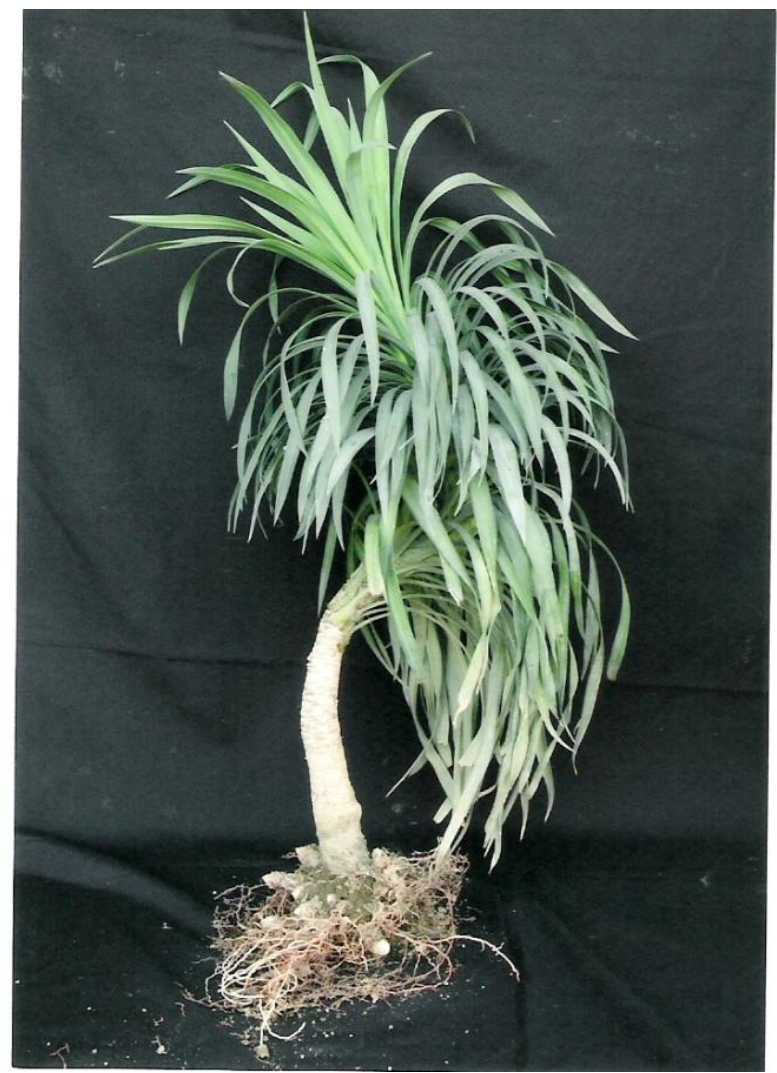

Fig.5 Yucca (Yucca schidigera) root

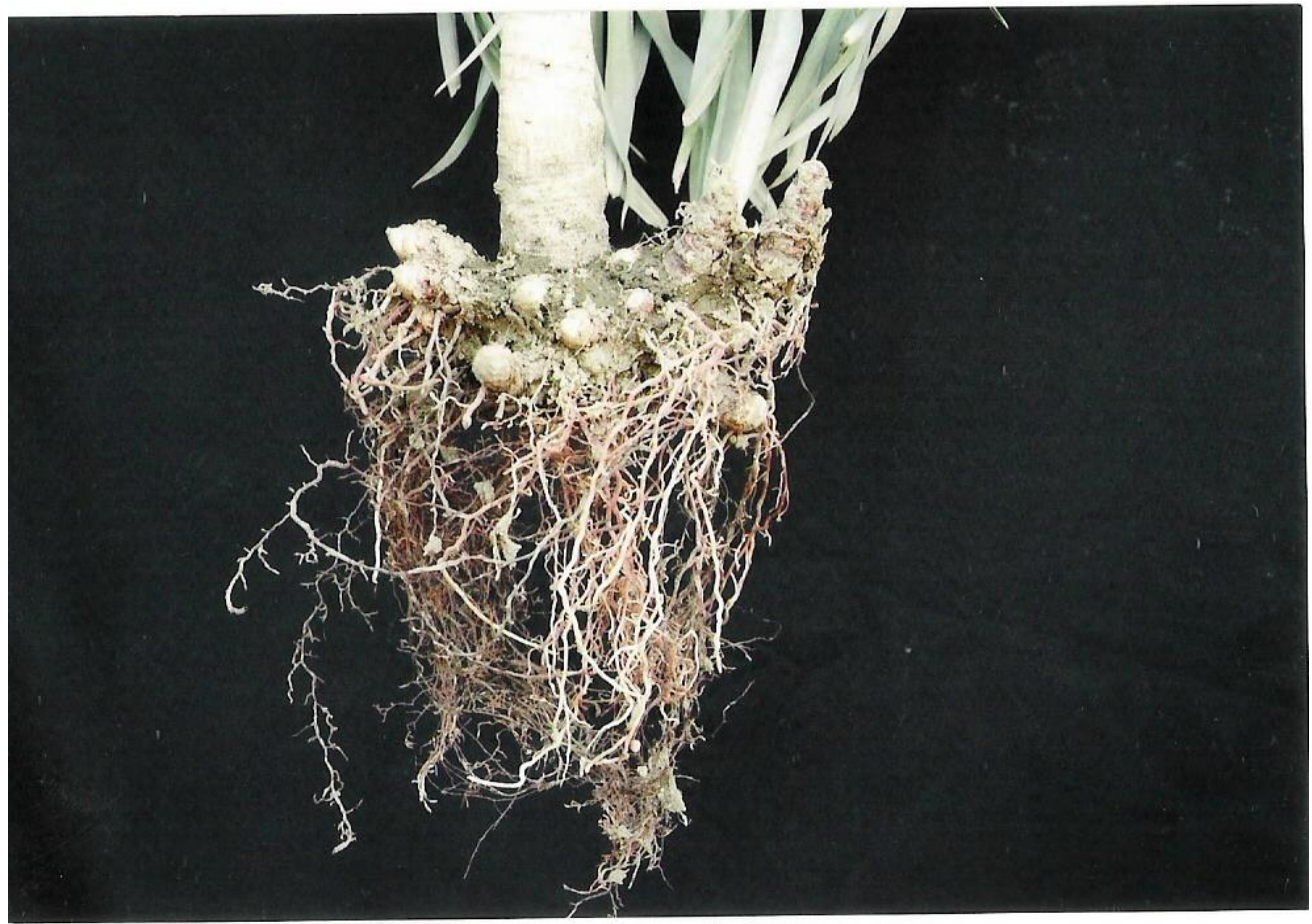


Fig.6 Siris (Albizia lebbek) leaves

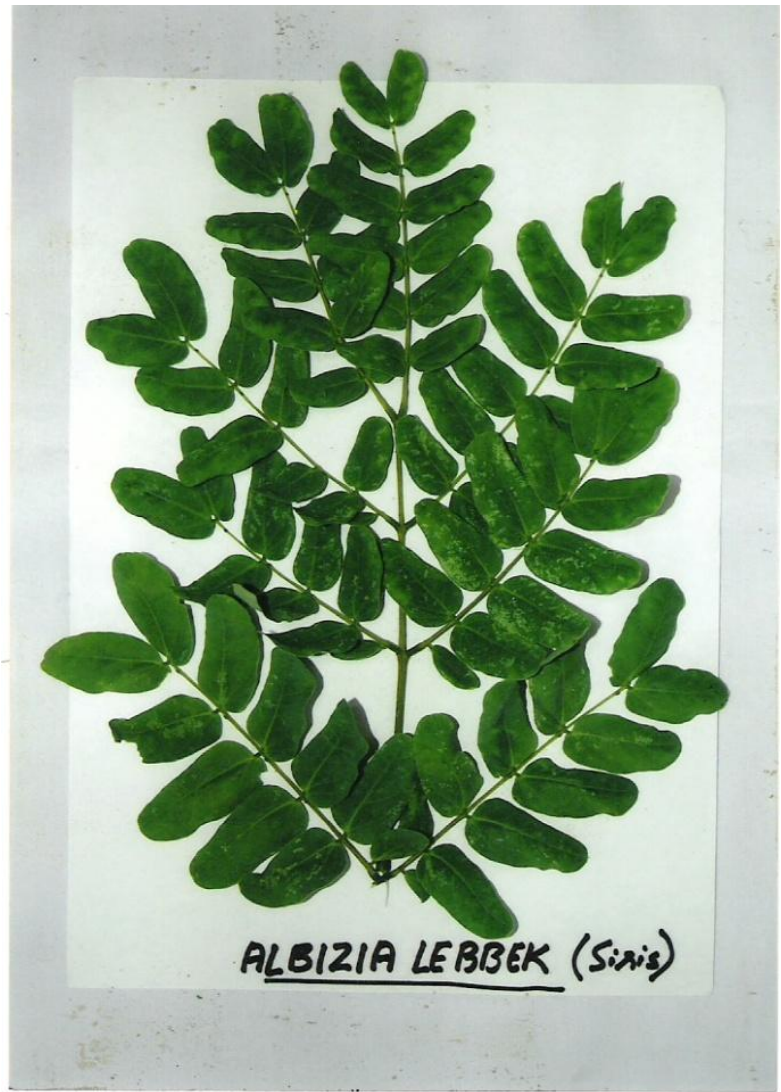

Total saponins content of Reetha, Shikakai, Mahua cake and Albizia leaves were found to be $8.74,11.79,7.34$ and $3.75 \%$, respectively. Total saponins content in various parts of Yucca plant i.e. leaves, root and stem was found to be $3.74,4.02$ and $2.80 \%$, respectively. It is evident from the given data that root was having maximum saponins content, whereas in the stem it was least. Total saponins content was found to be maximum in Shikakai (11.79\%) followed by Reetha $(8.74 \%)$ whereas minimum was found in Yucca stem $(2.80 \%)$. Saponins content of Reetha and Shikakai were estimated to be 4.51and 3.71\%, respectively by Malik (2007).

\section{Nitrogen content of plant extracts}

Nitrogen content $(\mathrm{mg} / \mathrm{ml})$ in plant extract of Reetha, Shikakai, Mahua cake, Albizia leaves and Yucca root was found to be 2.59, 1.96,
$0.98,1.33$ and 1.68 , respectively. It was evident from the given data that Reetha was having the maximum amount of soluble nitrogen followed by Shikakai, whereas Mahua cake is having the least amount of soluble nitrogen content.

To achieve the saponins level at 2 and 4 percent of total mixed ration during in vitro study, the plant extracts were added to the ration and the quantity of each plant extract has been presented in table 4 .

On the basis of present study on the determination of proximate principles of Reetha, Shikakai, Mahua cake, Albizia leaves and Yucca roots, stem and leaves and quantification of total saponins in them, it was concluded that total saponins content was highest in shikakai powder $(11.79 \%)$ followed by Reetha powder $(8.74 \%)$ and lowest in 
Yucca stem $(2.80 \%)$. The organic matter content in Yucca roots was highest whereas in Albizia leaves it was lowest as 98.42 and 88.14 percent, respectively. The NDF content in these plant materials varied in a narrow range except in Albizia leaves, which was having highest NDF content (41.44\%). Thus based on the above findings it can be said that these indigenous plants extracts rich in saponins and can be employed to modify rumen microbial fermentation.

\section{Acknowledgement}

The first author sincerely acknowledges Director ICAR-NDRI for awarding fellowship and required facilities for this study.

\section{References}

Alexander, G., 2005. Effect of plant extracts on rumen fermentation and nutrient utilization in sheep. Ph.D. Thesis, Indian Veterinary Research Institute (Deemed University), Izatnagar (UP).

AOAC, 1995. Official Analytical Methods. Association of Official Analytical Chemists, Washington, DC.

Babayemi, O.J., Demeyer, D. and Fievez V. 2004. Nutritive value and qualitative assessment of secondary compounds in seeds of eight tropical browse, shrub and pulse legumes. Agric Appl.Biol.Sci.69:103-10.

Balgees, A., Fadal Elseed, A.M. and Salih, A.M. 2015. Effects of Albizia Lebbeck or wheat bran supplementation on intake, digestibility and rumen fermentation of ammoniated bagasse. http://khartoumspace.uofk.edu/handle/1 23456789/17631.

Busquet, M., Calsamiglia, S., Ferret, A. and Kamel, C. 2005. Screening for effects of plant extracts and secondary plant metabolites on rumen microbial fermentation. Anim. Feed Sci. Technology. 124: 597-613.

Cardozo, P.W., Calsamiglia, S., Ferret, A. and Kamel, C. 2004. Effects of natural plant extracts on rumen protein degradation and fermentation profiles in continuous culture. J. Anim. Sci., 82: 3230-3236.

Chahil, S.M., Singhal, K.K. and Sharma, D.D. 1987. Mahua byproducts and their utilization. Indian Dairyman. 39: 459461.

Davidson, P.M., and Naidu, A.S. 2000. Phytophenols. Natural Food Antimicrobial Systems. Ed. CRC Press, Boca Rotan, FL, 265-293.

Delgado, D.C., Galindo, J., González, R., González, N., Scull, I., Dihigo, L., Cairo, J., Aldama, A.I. and Moreira, O. 2012. Feeding of tropical trees and shrub foliages as a strategy to reduce ruminal methanogenesis: studies conducted in Cuba. Trop Anim Health Prod. 44:1097-1104.

FDA, 2004. Food and Drug Administration of the US, 21 CFR 184 http://www.cfsan.fda.gov/ird/fcf184, html, Accessed Sep.20, 2004.

Hess, H.D., Kreuzer, M., Diaz, T.E., Lascano, C.E., Carulla, J.E., Soliva, C.R. and Machm"uller, A. 2004. Saponin rich tropical fruits affect fermentation and methanogenesis in faunated and defaunated rumen fluid. Anim. Feed Sci. Technol. 109, 79-94.

Hiai, S., Oura, H. and Nakajima, T. 1976. Color reactions of some sapogenins and saponins with vanillin and sulphuric acid. Planta Medica. 29: 116-122.

Kamra, D.N., Agarwal, N. and Pathak, N.N. 2000. Soapnut as a defaunating agent its effect on rumen fermentation and in sacco degradability of jowar hay in buffaloes. Buffalo J. 16: 99-104.

Lila, Z.A., Mohammed, N., Kanada, S., Kawada, T. and Itabashi, H. 2003. Effect of sarsaponin on ruminal 
fermentation with particular reference to methane production in vitro. J. Dairy Sci.86: 3330-3336.

Malik, P.K., 2007. Effect of dietary leguminous fodder on methane and nitrous oxide emission from ruminants. Ph.D. Thesis submitted to National Dairy Research Institute (Deemed University, Karnal).

Patra, A.K., Kamra, D.N. and Agarwal, N. 2006b. Effect of plants containing secondary metabolites on in vitro methanogenesis, enzyme profile and fermentation of feed with rumen liquor of buffalo. Anim. Nutr. Feed Technol. 6, 203-213.

Sliwinski, B.J., Soliva, C.R., Machmuller, M.A. and Kreuzer, M. 2002. Efficiency of plant extracts rich in secondary constituents to modify rumen fermentation. Anim. Feed. Sci. Technol. 101: 101-104.

Van Soest, P.J., and Robertson, J.B. 1985. Analysis of Forages and Fibrous Foods. AS 613 Manual, Department of Animal Sciences, Cornell University, Ithaca, USA.

\section{How to cite this article:}

Anamika, K.K. Singhal, A.K. Singh and Shilpi Kerketta. 2017. Nutritional Evaluation of Indigenous Plants and Quantification of Total Saponins in Plant Extracts. Int.J.Curr.Microbiol.App.Sci. 6(9): 1368-1377. doi: https://doi.org/10.20546/ijcmas.2017.609.166 